\title{
Experimental Analysis of an Air Storage Tank in Wind Driven Ventilation System
}

\author{
Giedré Streckienè $\dot{1}^{1, *}$, Juozas Bielskus ${ }^{1}$, Dovydas Rimdžius $^{1}$, Vytautas Martinaitis ${ }^{1}$ and Violeta Motuziene் $\dot{\mathrm{e}}^{1}$ \\ ${ }^{1}$ Department of Building Energetics, Vilnius Gediminas Technical University, Sauletekio ave. 11, 10223, Vilnius, Lithuania
}

\begin{abstract}
With the growing demand for energy efficient HVAC systems and integration of renewable energy sources, existing energy transformers are being improved and new solutions are being sought. Various energy storage technologies are applied to solve unpredictable renewable energy flows. This paper investigates an innovative ventilation system with roof turbine ventilator and variable volume isobaric air tank, which is used to store an excessive wind energy. The study focuses mainly on isobaric air storage tank operation. The experimental results of the tank charging and discharging processes under different operation conditions are presented. These conditions include different weights placed on the top of the storage and air flow rates in the wind tunnel. The operation of the tank during one windy day in chosen location is studied. The obtained data showed the initial results of the operation of the developed ventilation system and possible modifications in order to improve its functionality.
\end{abstract}

\section{Introduction}

Wind energy offers many advantages, which explains why it is one of the fastest-growing energy sources in the world. Wind is used to generate electricity as well as to ventilate buildings. A major limitation of naturally ventilated techniques in general is the unpredictability of the driving forces. Relevance of fluctuations of the wind energy in ventilation systems is discussed by $[1,2]$. Wind energy storage could be a solution to increase reliability of the wind driven ventilation systems.

There exists a technology used in wind power plants - compressed air energy storage (CAES), which operates in the way of storing energy in the form of high-pressure compressed air during the periods of low electric demand and then releasing the stored compressed air energy to generate the electricity to meet high demand during the peaks. A detailed review on various aspects of a CAES system has been made and presented in [3]. Meanwhile, considering the potential of compressed air storage for natural ventilation, there is a lack of research on the combinations of ventilation and compressed air storage. HVAC systems energy storage is quite common, however, in most cases, research in the field of mechanical ventilation only can be noted, e.g. in [4-7].

In this study, an innovative ventilation system with roof turbine ventilator (RTV) and isobaric air storage tank is proposed. In addition, it is analysed wind storage potential for RTV's functionality increase. The presented system uses only renewable wind energy. Although the system is designed to extend the ventilation functionality, such air storage tank could be applied to other systems that require a pressure of $1000 \mathrm{~Pa}$ or less. The analogy with CAES systems provides a better understanding of operation models and analysis techniques of the proposed storage system. The aim of this study is to experimentally assess the operation of an air storage tank of the innovative ventilation system under different wind conditions and weight loads. The developed system enables to store excess wind energy and alter use it to expand the functionality of the ventilation system. The energy is stored in the form of compressed air.

\section{Methodology and experimental system}

\subsection{Description of the experimental system}

The scheme of the developed system is shown in Fig. 1. It consists of the roof turbine ventilator (RTV) (2) and turbofan (4) that are mounted on the roof of the building and other equipment (air tank of variable volume (3), gearbox with axle connecting to the RTV (5)) which is placed in the room. A description of the experimental set-up and its operation is presented further.

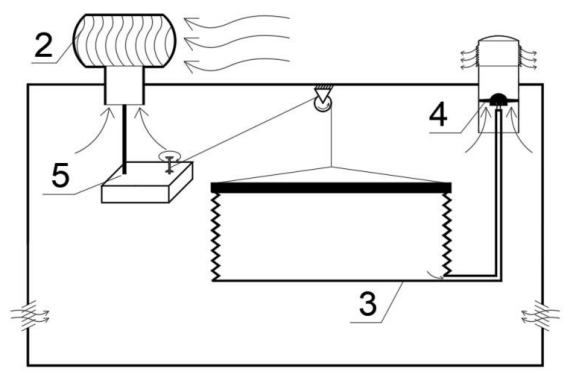

Fig. 1. The schema of the developed system.

* Corresponding author: giedre.streckiene@ vgtu.lt 
The view of the experimental set-up is presented in Fig. 2. The construction consists of the main following components: a wind tunnel (1), which is in detail described in [8], roof turbine ventilator (RTV) (2), isobaric air tank (storage) of variable volume (3) (area of $0.5 \mathrm{~m} \times 0.5 \mathrm{~m}$, max possible height of $1.8 \mathrm{~m}$, made of mechanically rigid material), turbofan (4) and the gearbox (5). A detailed study of used RTV ("Hurricane H100") was presented in [8], where the dependencies of extracted air flow rate and other characteristics on wind velocity were examined. In addition, this system uses a clutch for connecting and disconnecting the shaft of the RTV to the gear-box (multi-stage gear transmission). Pressure stabilization boxes are used to equalize the pressure between the environment and the ventilated test room.

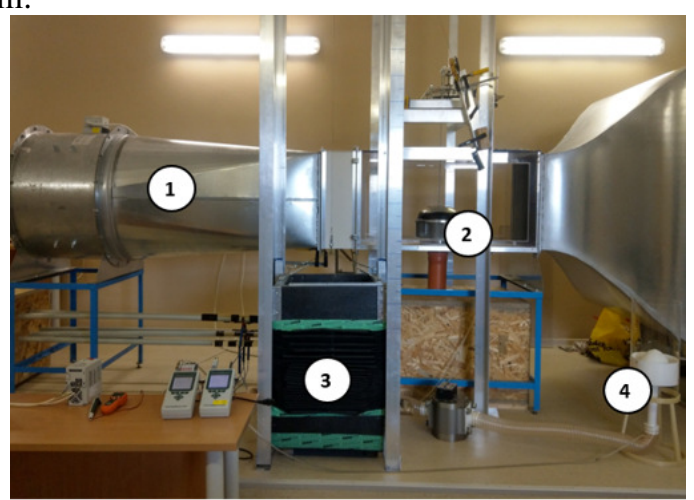

a)

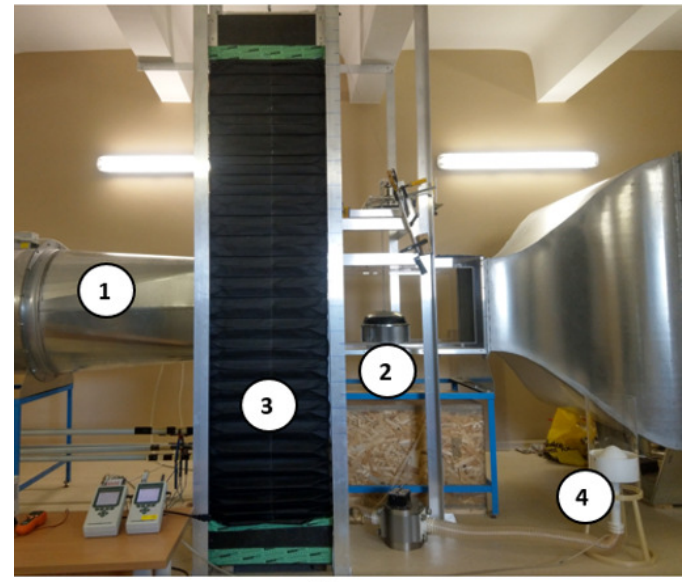

b)

Fig. 2. Experimental set-up: a) storage tank at the beginning of the charging process; b) storage tank at the end of the charging process.

Steps of the experimental procedure:

1. Initially, the required air flow rate (imitation of wind) is created in the wind tunnel. The RTV starts to rotate together with the gear-box, which is connected via common axis.

2. When airflow is sufficient $(>5 \mathrm{~m} / \mathrm{s})$, the clutch is engaged, rotation of the cable starts on the outgoing gear-box axle and the bellows with weight load lift (4 different weight were tested, they are expressed as loads in Table 1). At the same time, the volume of the tank increases ( $\max$ height $1.8 \mathrm{~m}$ ). A certain tested weight is placed on the top of the storage tank.
3. When the bellows are raised to the maximum height, the storage state is reached. Next, the axis of rotation is disconnected from the output of the gear-box.

4. When the demand for ventilation arises, but RTV does not rotate, bellows with weight load are released to fall freely. Their landing creates the pressure increase, which depends on the load. The pressure and the volume of the storage tank drops rapidly.

5. When the tank is emptied, the cycle of charging and discharging is repeated.

Measurement equipment used during the experiments includes: AHLBORN multichannel data logger ALMEMO 2890-9 for registration the pressure and RTV extracted air flow rate. A differential pressure sensor with measuring range of $\pm 1250 \mathrm{~Pa}$ and a rotary anemometer of $0.3-20 \mathrm{~m} / \mathrm{s}$ was connected to this data logger. Electronic scale with a maximum measurable weight of up to $440 \mathrm{~N}$ and a measuring step of $0.1 \mathrm{~N}$ were used to determine the dynamic load of storage tank with a tested weight.

At the start point of the cycle, the system is shown in Fig. 2 a) - the storage tank starts to accumulate the air; it is almost empty. Fig. 2 b) represents the maximum volume of the tank before the discharge. These experiments included tests with different air flow rates in the wind tunnel and different weight loads (Table 1) for storage tank. During both charging and discharging cycles of the tank, a total load force includes weight, friction and deformations forces. Experiments started by loading the tank with the lowest weight.

Four weights were tested to determine possibilities of the system performance. This allowed to analyse resulting pressures in the tank and determine limiting cases (when wind energy/velocity is insufficient to lift the weight). In addition, such analysis gives insights which load is more appropriate to use in one or other case depending on the objective. As different weights were lifted from a height of 0 to $1.8 \mathrm{~m}$, the distribution of loads depending on the height of the tank is presented in Table 1.

Table 1. Weights and loads used in the experiment.

\begin{tabular}{|c|c|c|c|c|}
\hline \multirow{2}{*}{$\begin{array}{c}\text { Height of } \\
\text { bellows, } \mathrm{m}\end{array}$} & \multicolumn{4}{|c|}{ Weights, N } \\
\cline { 2 - 5 }- & $\mathrm{W} 1$ & $\mathrm{~W} 2$ & $\mathrm{~W} 3$ & $\mathrm{~W} 4$ \\
\hline & 117 & 166 & 215 & 264 \\
\hline 0.0 & 0 & 0 & 0 & 0 \\
\hline 0.5 & 133 & 182 & 231 & 280 \\
\hline 1.0 & 145 & 194 & 243 & 292 \\
\hline 1.8 & 171 & 220 & 269 & 318 \\
\hline
\end{tabular}

One of such cycles (charging-discharging) is illustrated in Fig. 3. In this case, the load W2 is used and the wind speed is maintained at $8.9 \mathrm{~m} / \mathrm{s}$. The black line represents actual process during the experiment and the red line shows the ideal discharging process. 


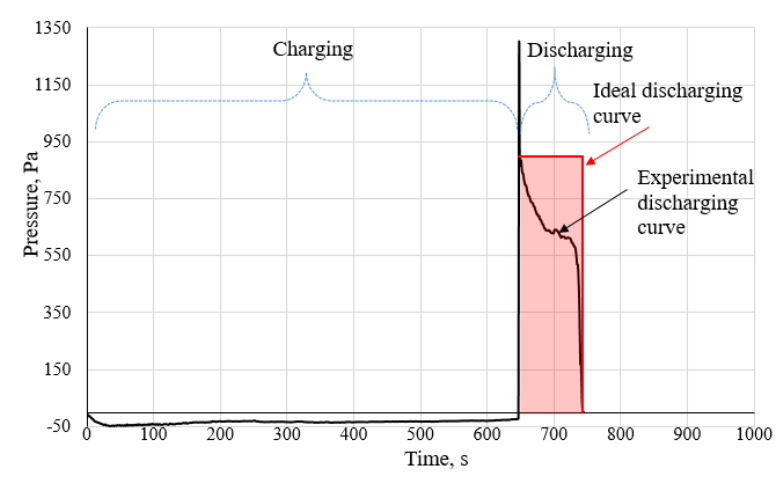

Fig. 3. Charging and discharging process of the analysed system, $\mathrm{W} 2$ and $v=8.9 \mathrm{~m} / \mathrm{s}$.

During the experiments, the performed cycle includes only charging and discharging phases without storage. As can be seen from Fig. 3, charging lasted 647 s until the bellows reached the maximum height. During the charging, a negative pressure was recorded (up to 49.4 $\mathrm{Pa})$ as air was pumped through a non-return valve. Due to the design of the tank, the initial dynamic pressure occurred when the load (W2) started to fall down. Firstly, the pressure dropped suddenly from $1276 \mathrm{~Pa}$ to $867 \mathrm{~Pa}$. This is because walls of the storage tank are initially deformed by high pressure and at the same time, the volume of the tank increased until it reached the final shape. Further, the pressure gradually decreased until the deformation of the storage walls stabilized and the pressure became close to constant. For this reason, the air tank could be considered as isobaric. Friction losses influenced the further pressure drop. At the end of the discharging process, the pressure dropped suddenly again and the storage tank was discharged. The total discharging process took $95 \mathrm{~s}$. During discharge, 300 J of work is done by the system.

Depending on the selected load and its lifting weight, different pressures can be achieved. The maximum possible height of the load is $1.8 \mathrm{~m}$. In the case of $\mathrm{W} 1$, the maximum measured pressure was $1400 \mathrm{~Pa}$ and during the longest discharge period pressure was maintained at $\sim 1000 \mathrm{~Pa}$. At the lowest load W4, the maximum pressure was $700 \mathrm{~Pa}$ and the constant pressure during discharging was $\sim 500 \mathrm{~Pa}$, respectively.
It can be seen that due to the effect of friction and deformation forces, the actual line of pressure change differs from the ideal process line. Various efficiencies are used for the evaluation of CAES [9]. Comparing the actual ideal discharging process (if a pressure of $900 \mathrm{~Pa}$ is maintained during ideal process), the pressures during the processes are integrated below the corresponding curves. The discharging efficiency of the actual process of $71.7 \%$ is obtained, this shows the demand to improve the design of the storage tank.

\subsection{Case study area}

The case study was performed in the city of Vilnius, Lithuania. The wind velocity profile data has been collected from a meteorological station which is set up on the roof of Vilnius Gediminas Technical University, Lithuania $\left(54.72247^{\circ} \mathrm{N}, 25.33548^{\circ}\right.$ E) (Fig. 3). Usually the average wind velocity in Vilnius is $3.5-4 \mathrm{~m} / \mathrm{s}$ [10]. However, there are certainly a number of wind velocity fluctuations well above the average. Therefore, one winter day was selected when higher wind velocities were recorded. The analysis of this day is shown in the next section.

\section{Results and discussion}

Charging and discharging processes of the air tank (storage) at different loads (W1, W2, W3 and W4) and wind velocities $(5 ; 6 ; 7.2$ and $8.9 \mathrm{~m} / \mathrm{s})$ are shown in Fig. 4. It should be noted that in the selected case, the same load was tested to charge and discharge the air tank at the selected air flow rate.

As can be seen from Fig. 4, the same trend (see Fig. 3) of the discharging processes can be observed. Solid lines represent the case when weight loads are lifted at constant wind speed of $8.9 \mathrm{~m} / \mathrm{s}$. At the same time, the ratios between time periods of the storage tank charging and discharging are analysed. Using the lightest load (W1), the charging takes the shortest time (556 s) and the discharging - the longest time (115 s), respectively. Thus, the charging/discharging ratio is equal to 4.8 .

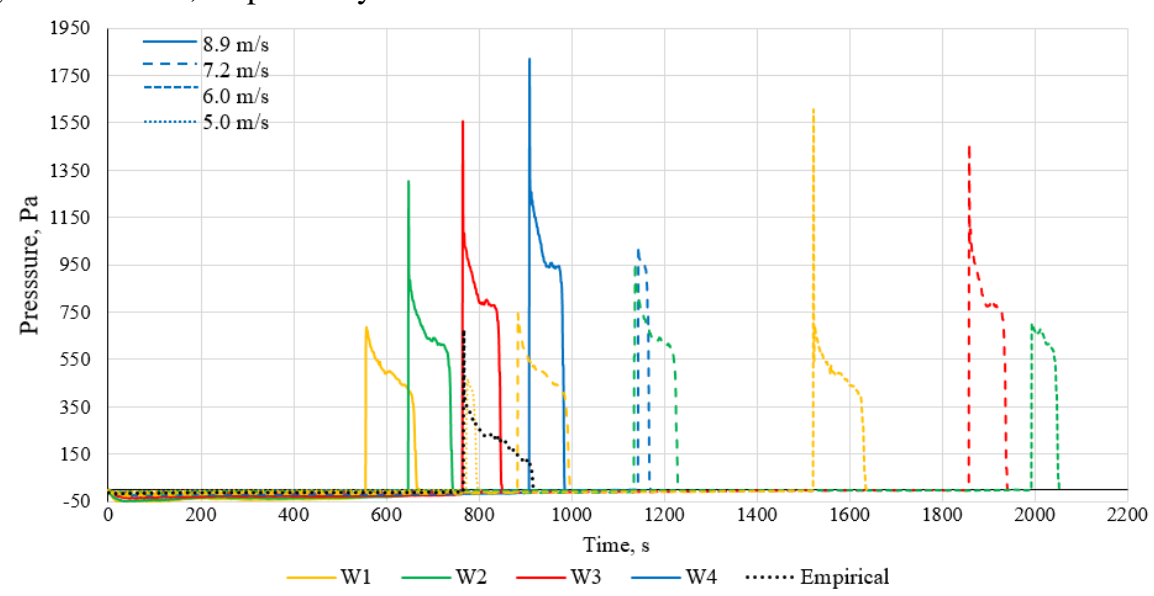

Fig. 4. Charging and discharging of the storage tank depending on wind velocity and load. 
If we take another limiting case (W4), the air tank charge took $906 \mathrm{~s}$ and discharge - $75 \mathrm{~s}$. The charging/discharging ratio is 12.1 . When the wind velocity decreases to $7.2 \mathrm{~m} / \mathrm{s}$ charging period lasts longer: W1 case $-883 \mathrm{~s}$, W2 case $-1134 \mathrm{~s}$, W3 case $1857 \mathrm{~s}$ and W4 case $-1143 \mathrm{~s}$, respectively. It should be noted that in the case of W4 the air tank is not fully charged (the load was not raised to height of $1.8 \mathrm{~m}$ ), so a shorter discharging time is also determined. If the case $\mathrm{W} 1$ is considered, almost the same discharging time is achieved $114 \mathrm{~s}$. By maintaining a lower wind speed of $6 \mathrm{~m} / \mathrm{s}$, only loads W1 and W2 can be lifted. In the case of $\mathrm{W} 1$, the charging lasted $1522 \mathrm{~s}$, the discharging took $116 \mathrm{~s}$, thus the charging-discharging ratio increased to 13.1. In the case of W2, the charging took $1992 \mathrm{~s}$, however, the storage tank was not filled fully and discharging lasted only $60 \mathrm{~s}$. Applying the constant wind speed of $5 \mathrm{~m} / \mathrm{s}$ (design velocity for RTV operation), only the lowest load (W1) can be lifted and unfortunately the air tank is not fully charged.

Based on the experimental charging and discharging data, an empirical load is calculated which would allow to have discharging pressure of $\sim 200 \mathrm{~Pa}$. The determined load of this case is equal to $71 \mathrm{~N}$. Such empirical charging and discharging cycle when wind velocity is $5 \mathrm{~m} / \mathrm{s}$ is presented by black dotted line in Fig. 4. The calculated charging process takes $766 \mathrm{~s}$, the discharging - $152 \mathrm{~s}$, and the charge/discharge ratio is only 5. At higher wind velocities, this ratio would decrease further what is desirable.

Fig. 5 shows the dependency of RTV's extracted air flow rate depending on the wind speed and used load. As can be seen, heavier load results in worse extraction of the RTV. The case W0 means that RTV operates freely without storage possibility. The extracted air flow rate varies linearly, but in the case of heavier loads and lower wind speeds, air extraction is not performed (RTV does not rotate), and the air storage tank is not charged. Using this experimental data, the extracted air flow rates under variable wind conditions are determined by interpolation and used for the air tank performance analysis during the selected day (Fig. 6).

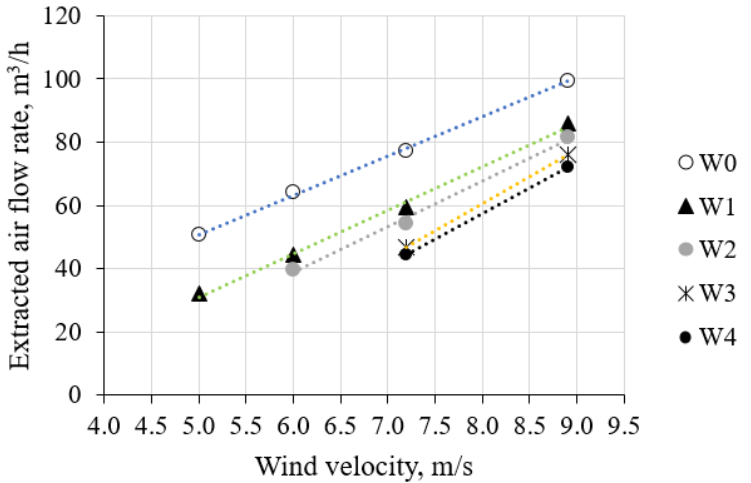

Fig. 5. Extracted air flow rate depending on weight and wind velocity.

One actual winter day of Vilnius city $-12^{\text {th }}$ of December is selected for the real case, see Fig. 6. During that day wind velocity was significantly higher at night time than the average wind velocity in that area, and wind velocity decreased during the day time. In addition, Fig. 6 shows the air flow rate supplied to the air tank. For the detailed analysis of the air tank chargingdischarging cycles the first three hours of that day were selected (Fig. 6 and Fig. 7).

It can be seen from Fig. 7 that only in the case of W1 the air tank is charged three times, in the case of W2 twice, and in the cases $\mathrm{W} 3$ and $\mathrm{W} 4$ a similar results are obtained - one full charge and discharge cycle. In addition, in the case on $\mathrm{W} 1$, the storage phase is observed in the first cycle when the air tank is fully charged and the wind velocity of $>5 \mathrm{~m} / \mathrm{s}$ is still recorded, the discharging starts only in case of insufficient wind velocity.

The analysis of full day shows that air tank with load W1 undergoes 12 charging/discharging cycles, with load W2 - almost 8 such cycles, and with loads W3 and W4 only three cycles. Therefore, in the present case, the air storage tank operates most efficiently only with load W1. It allows to utilize lower wind velocities for charging the air tank and reaches longer discharging time compared to other used loads. Evaluating the functionality of the ventilation system, its operation time was extended by $1.7 \%$ on that day using load W1.

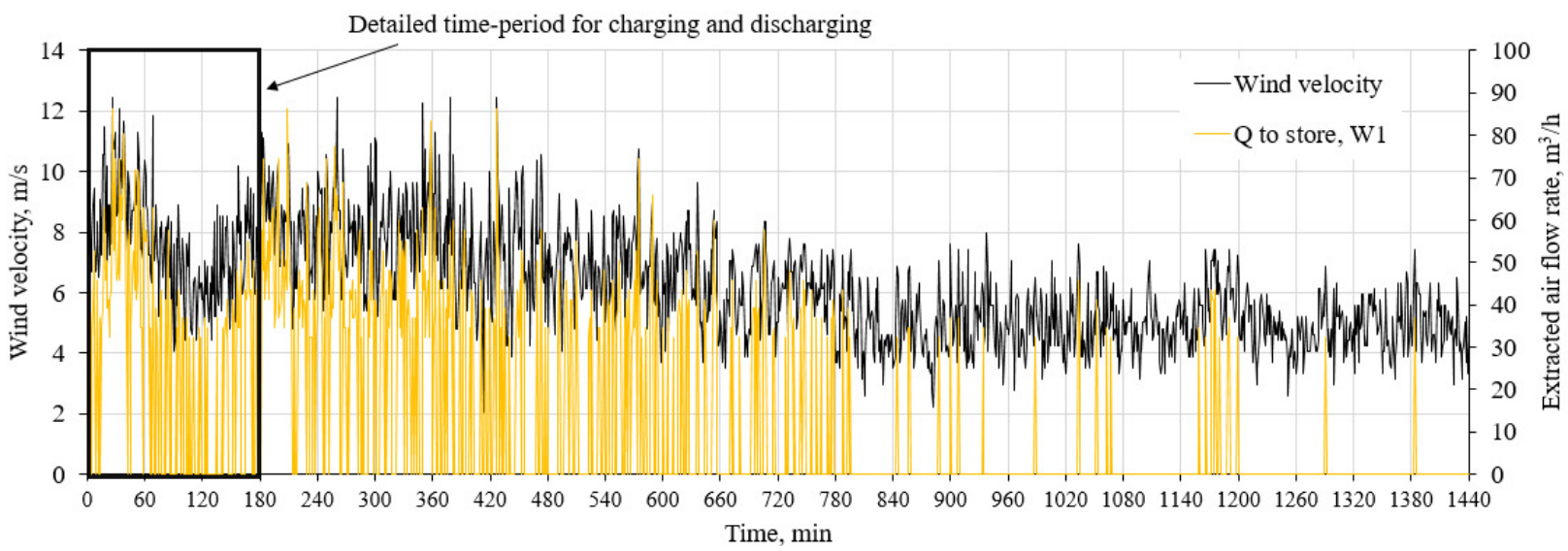

Fig. 6. Wind velocity and extracted air flow rate in the case W1. 


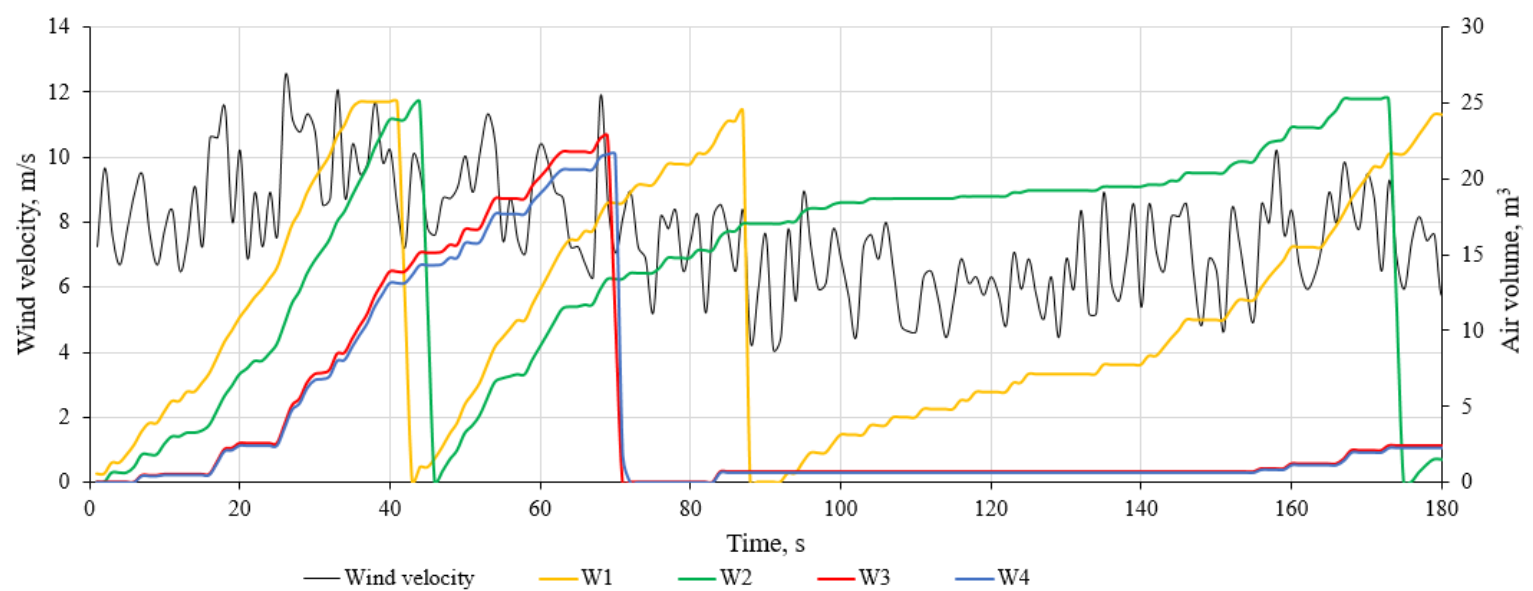

Fig. 7. Charging and discharging processes during the selected time-period.

If we apply a lower load (Fig. 4, empirical load), it would allow to achieve better results in increasing the operational functionality of the ventilation system. At the same time, the experimental results show that the selected weight is suitable only for a certain wind velocity. This demonstrates the need to use a variable load during both charging (which depends on the wind speed) and discharging process when it is sufficient to have lower pressures.

\section{Conclusions}

A novel idea of wind driven ventilation system with RTV and air tank (storage) has been experimentally tested and analysed. The experimental study showed how the system operates at the design wind velocity and over design velocities. The use of different loads for charging and discharging air tank enabled to identify its behaviour trends and to formulate recommendations for the selection of the appropriate load. When testing different loads, it has been found that the discharging of the air tank depending on the load can take from $75 \mathrm{~s}$ to $152 \mathrm{~s}$ if the tank is fully charged. The charging process is highly dependent on wind speed as well as on the load and not all loads are suitable for smaller wind speed (less tank $7.2 \mathrm{~m} / \mathrm{s})$. The following recommendations were made:

1. To prolong the time of discharging process, modifications of the geometrical parameters of the storage tank are required, as well lower achieved pressures could be used according to the application.

2 . The installation of such system for indoor ventilation when building or object is in a windier area would allow to increase the number of charging-discharging cycles together with the utilization of the accumulation potential and decreasing impact of wind energy fluctuations.

3. The use of variable load during both charging and discharging of the air tank would increase the functionality of the system.

The technology readiness level of the presented system is between the experimental proof of the concept and the technology validated in lab readiness stages.
Further improvement of its design and cost-benefit evaluation are planned in the future product development levels.

\section{Acknowledgements}

This project has received funding from the European Regional Development Fund project No 01.2.2-LMT-K-718-01-0016 under a grant agreement with the Research Council of Lithuania (LMTLT).

\section{References}

1. B. J. He, L. Ding, D. Prasad, J. of Build. Eng., 29, 101145 (2020).

2. F. Haghighat, H. Brohus, J. Rao, Build. \& Env., 35, 377-85 (2000).

3. G. Venkataramani, P. Parankusam, V. Ramalingam, J. Wang, Renew. Sustain. En. Rev., 62, 895-907 (2016).

4. B. Bozkaya, W. Zeiler, App. Th. Eng., 146, 190-202 (2018).

5. M. Alizadeh, S. M. Sadrameli, Renew. Sustain. En. Rev., 58, 619-45 (2016).

6. R. Barzin, J. J. J. Chen, B. R Young, M. M Farid, App. En., 158, 412-21 (2015).

7. X. Chen, Q. Zhang, Z. Zhai, En. \& Build., 118, 339-49 (2016).

8. D. Rimdžius, J. Bielskus, V. Martinaitis, V. Motuzienè, G. Streckienè, E3S Web of Conferences, ICPRE 2018, $20183^{\text {rd }}$ Int. Conf. on Power and Renewable Energy, 64, 07003 (2018).

9. F. Kaiser, R. Weber, U. Krüger, Int. J. Thermodyn., 21, 144-56 (2018).

10. G. Streckienè, V. Motuzienè, D. Rimdžius, V. Martinaitis, J. Bielskus, E3S Web of Conferences 64, 2018 3rd Int. Conf. on Power and Renewable Energy, 64, 07002 (2018). 